\title{
Dynamic Modelling, Experimental Identification and Computer Simulations of Non-Stationary Vibration in High-Speed Elevators
}

\author{
Radomir Đokić1,* - Jovan Vladić1 - Milan Kljajin² - Vesna Jovanović 3 - Goran Marković4 - Mirko Karakašić5 \\ ${ }^{1}$ University of Novi Sad, Faculty of Technical Sciences, Serbia \\ 2 University North, University Center Varaždin, Croatia \\ ${ }^{3}$ University of Niš, Faculty of Mechanical Engineering, Serbia \\ ${ }^{4}$ University of Kragujevac, Faculty of Mechanical and Civil Engineering in Kraljevo, Serbia \\ 5 University of Slavonski Brod, Mechanical Engineering Faculty, Croatia
}

\begin{abstract}
Modelling the dynamic behaviour of elevators with high lifting velocities (contemporary elevators in building construction and mine elevators) is a complex task and an important step in the design process and creating conditions for safe and reliable exploitation of these machines. Due to high heights and lifting velocities, the standard procedures for dynamic exploitation are not adequate. The study presents the method of forming a dynamic model to analyse nonstationary vibrations of a rope with time-varying length with nonholonomic boundary conditions in the position where the rope is connected with the cabin (cage) and in the upcoming point of its winding onto the pulley (drum). A unique method was applied to identify the basic parameters of the dynamic model (stiffness and damping) based on experimental measures for a concrete elevator. Due to the verification of this procedure, the experiment was conducted on a mine elevator in RTB Bor, Serbia. Using the obtained computer-experimental results, the simulations of the dynamic behaviour of an empty and loaded cage were shown. In addition, the study shows the specific method as the basis for forming a control program that would enable the decrease in vertical vibrations during an elevator starting and braking mode.
\end{abstract}

Keywords: high-speed elevators, dynamic analysis, a rope with time-varying length, mechanical characteristics of steel ropes, longitudinal oscillations, control program

\section{Highlights}

- The complexity of the dynamic analysis of elevators is because these are systems for lifting (lowering) people and load to great heights (depths) with high velocities and variable parameters.

- Determining the critical hoisting velocity of the elevator car can be performed in the function with mechanical characteristics of ropes, such as the elasticity modulus and damping and loads in steel ropes.

- Based on the theory of free harmonic damping oscillations, the mechanical characteristics of steel ropes can be determined through the oscillation diagrams obtained by measurement.

- By defining the basis for the driving mechanism control program, it is possible to provide minimum dynamic loads of elevators based on adequate models and simulations of their operation in real conditions.

\section{INTRODUCTION}

Mines with underground exploitation and operating levels up to $2500 \mathrm{~m}$, along with the rising number of exceptionally tall buildings, with heights reaching up to $850 \mathrm{~m}$ nowadays - such situations require electric elevators with specific characteristics, whose velocity reaches up to $20 \mathrm{~m} / \mathrm{s}$, and load capacity up to over ten tons. The elevator quality is estimated according to several important indicators. Safety, comfort, and reliability are especially important features [1]. These indicators depend on, first of all, vibrations occurring while the elevator is in motion. Vibrations are a consequence of driving parameters, inertial characteristics and elasticity of the binding elevator elements. Fig. 1 shows the elements with the greatest impact.

An elevator can be divided into two basic parts according to the dynamic impact on the vibration values. The first part is a driving mechanism (engine, reductor, brake, and couplings), while the second part is a cabin lifting system, mostly made of steel ropes for lifting the counterweights on one end and cabin (cage) on the other end and their guide rails. The driving mechanism comprises elements that are much more rigid $\left(c_{1}, c_{2}\right.$, Fig. 1) and have a smaller mass than the cabin lifting system (c, Fig. 1), which in turn causes the oscillations in smaller amplitudes and higher frequencies. As well as that, bearing in mind that the oscillations are indirectly transferred to the cabin (cage) via ropes, it can be deduced that the lifting system has a much bigger influence on the comfort during the motion than driving mechanism elements does.

Deep shaft mines require special mining ropes to hoist personnel and materials safely and efficiently. They are made of round wires that must be either bright or galvanized. The values of the rope safety 
factors for hoisting in mines depend on shaft depth and rope number and are higher in the case of personnel hoisting. According to ISO standards for the area of mine elevators, safety factors vary between 4 and 8 for new ropes and between 3.6 and 6.4 for ropes to be discarded, depending on shaft depth. The highest value of 13 is required by special regulations for hoisting people to depths of up to $600 \mathrm{~m}$.

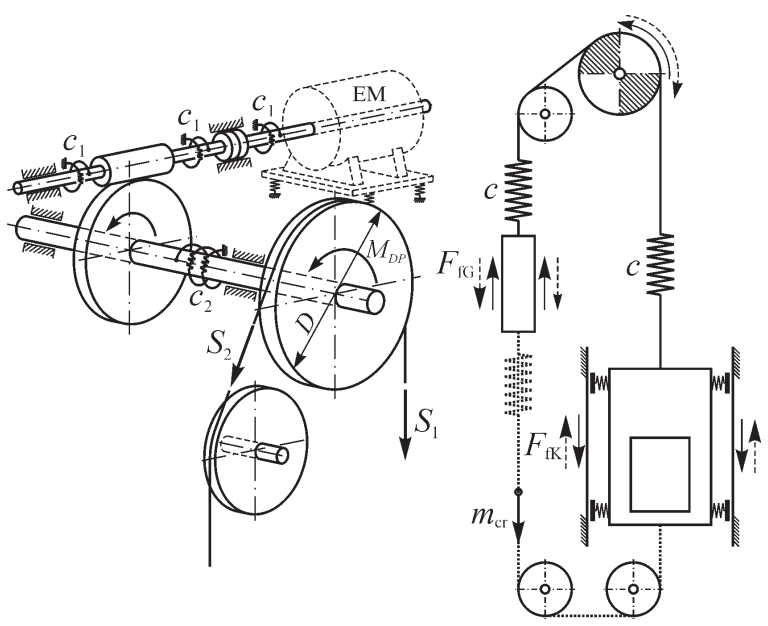

Fig. 1. Elements with the biggest impact on vibration occurrence in elevators

While the elevator is in operation mode, the hoist ropes increase and decrease their free length, so the parameters, such as rope stiffness and damping, are constantly changing [2] to [4]. In high-speed elevators, dynamic instability may occur during lifting (reducing free length) due to increased relative deformation. This instability seriously impacts the safety of the passengers. Since classic models are based on elastic body (rope) oscillations with constant dynamic parameters (mass, stiffness and damping), it is necessary to form dynamic models that will enable the analysis and definition of the dynamic behaviour of elevators with variable parameters [5] and [6].

Because special attention has to be paid to the accuracy of installing and making of cabin guide rails and counterweight in high-speed elevators, the following conclusion arises. Without the addition of external influences, it can be concluded that longitudinal oscillations are dominant, as opposed to transversal oscillations [7] and [8].

Taking into consideration that up until this moment, the problems in driving mechanism vibrations were the subject of a great number of scientific and research papers, with standard analyses as the most frequently applied method, it seems logical that the main focus of dynamic research of elevators should be pointed towards innovative methods for analysing the longitudinal oscillations with variable parameters [9].

\section{DYNAMIC MODELS FOR THE ANALYSIS OF ELEVATOR LONGITUDINAL OSCILLATIONS}

\subsection{Standard Models}

Many researchers are interested in studying longitudinal oscillations, and their studies have been based on the general theory about the application of oscillation of elastic bars with constant parameters (mass, stiffness, and damping). These are the socalled standard models [8] and [10]. Those models are acceptable for analysing elevators with low lifting velocities and heights. Figs. 2a and $b$ show models with one and two degrees of freedom and a rope of constant lengths, represented here as Hook's, i.e., Calvin's body.

A certain improvement has been made with the analysis of high-lift elevators $(\geq 35 \mathrm{~m})$ and low velocities (till $3 \mathrm{~m} / \mathrm{s}$ ) by using the model represented in Fig. 2c. The model represents a bar of a constant length with an equally spread mass $q(\mathrm{~kg} / \mathrm{m})$, i.e., it is a model of an elastic body with an unlimited number of degrees of freedom and a concentrated mass at the bottom end as the boundary condition.

Based on the analysis which was shown in detail in [11] to [14], in the case when the free rope length is small compared to the cabin mass, it is possible to significantly simplify the dynamic model analysis.

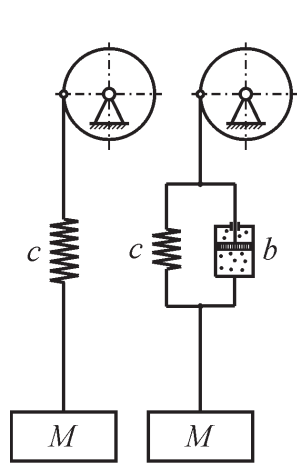

a)

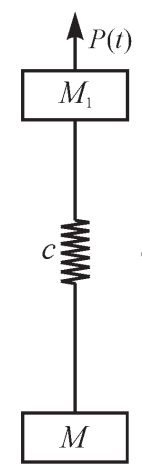

b)

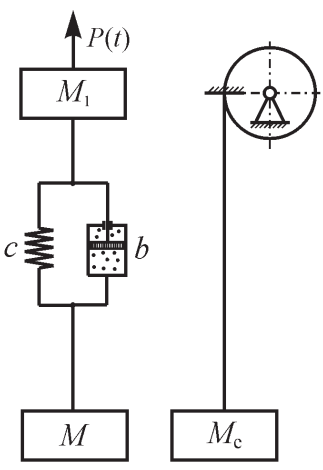

c)
Fig. 2. Standard dynamic models; a) with one degree of freedom; b) with two degrees of freedom; c) a "heavy" constant length bar

Fig. 3 shows an oscillation diagram for the first three harmonics. Due to the very small oscillation amplitudes in higher harmonics, their influence can be neglected. Thus, the total oscillation process with infinite degrees of freedom, whose total oscillation 
form is shown in Fig. 3 with a dashed line $(d)$, can be replaced with a straight line $(a)$, with satisfactory accuracy. In other words, it is replaced with a system with one degree of freedom and constant dilatation $(\varepsilon)$ along the free rope end.

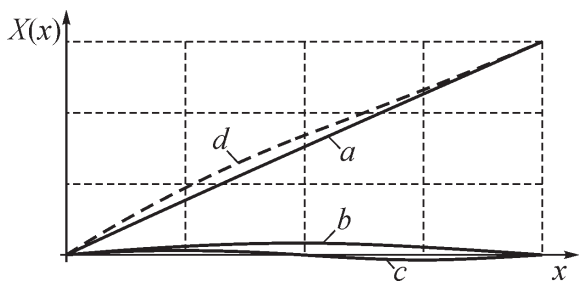

Fig. 3. Oscillation shapes (forms) of the first three harmonics ( $a, b$ and $c$ ), and the summary oscillation form for $\alpha=0.1$

In accordance with the above, regarding high-lift elevators ( $\geq 35 \mathrm{~m}$ ) and low velocities (to $3 \mathrm{~m} / \mathrm{s}$ ), it is roughly possible to create load oscillation models with one degree of freedom, with a "heavy" spring, which was studied in general literature. Also, it is necessary to replace the total mass (of both load and rope) with an equivalent mass $M_{\mathrm{e}}=M+(1 / 3) \cdot q L$, reduced in the cabin place, [15] and [16].

\subsection{Dynamic Elevator Models with Dynamic Variable Parameters}

Fig. 4a shows the most common solutions of the lifting systems for high-speed elevators with a driving pulley, while the corresponding dynamic model is shown in Fig. $4 b$.

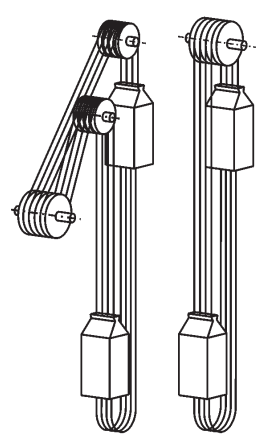

a)

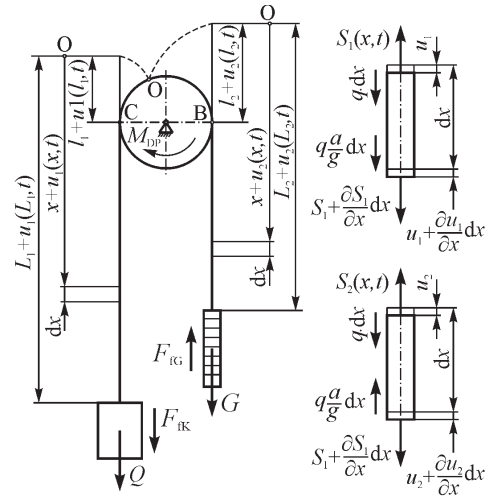

b)
Fig. 4. Elevator models; a) Köepe system, b) a dynamic model of a high-speed elevator

In order to secure comfort during the motion, control programs are used in contemporary elevators. They define the circumferential velocity of the pulley. Thus, they also define the cabin motion velocity (a kinematic condition), as opposed to the previous period when the motion velocity depended a great deal on the driving electromotor's mechanical characteristics and brake system (the dynamic equilibrium condition). In the earlier periods, replacing one-speed engines with two-speed engines was observed as a significant improvement. This improved the motion comfort in braking instances and aided the accuracy of stopping the cabin. As for the process of a regular elevator, in cases in which there is no slipping of the steel rope on the driving pulley and when the driving characteristic is represented via a rope velocity at the meeting point of the rope and pulley, the elevator model can be simplified and represented in the form shown in Fig. 5.

Upon observing just the upcoming rope end, the model can be represented as a system with an unlimited number of degrees of freedom; at one end it is rolling onto the pulley at a $v(t)$ velocity, while on the other it is burdened with concentrated mass. Due to the variable rope length during the motion, the stiffness $(c=E A / L)$ changes. This is a characteristic of parametric oscillations and contributes to the possible occurrence of resonance. To this end, it is necessary to complete certain steps in the analysis of dynamic behaviour. The critical lifting velocity, during which the unstable motion occurs, i.e., the rope strain is increased when its free length is reduced, needs to be determined.

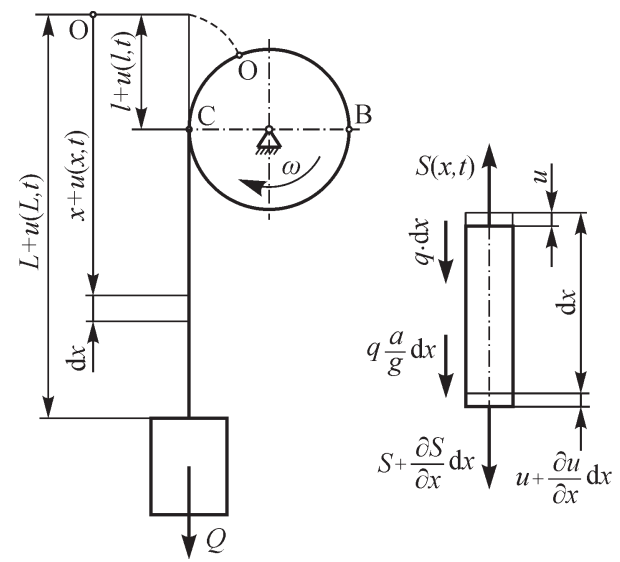

Fig. 5. Elevator model with a rope of a variable length with boundary conditions

The deformation of an arbitrary cross-section represents the function of the position $x$, and the time $t$, i.e.:

$$
u=f(x, t) .
$$

Upon observing the equilibrium of the elementary part $(d x)$, it can be deduced that: 


$$
\begin{aligned}
\frac{q \cdot d x}{g} \cdot \frac{\partial^{2} u(x, t)}{\partial t^{2}} & =-S(x, t)+S(x, t) \\
& +\frac{\partial S}{\partial x} d x+q \cdot d x \pm \frac{q \cdot d x}{g} \cdot a .
\end{aligned}
$$

By representing the rope as Calvin's model, where the influence of internal friction can be taken into consideration via the so-called rope resistance force factor $\left(b_{\mathrm{f}}\right)$, the dependence of the inner force in the rope on its deformation can be noted in this form:

$$
S(x, t)=E \cdot A \cdot \frac{\partial}{\partial x} \cdot\left[u(x, t)+b_{\mathrm{f}} \cdot \frac{\partial u(x, t)}{\partial t}\right] .
$$

If the Eq. (2) is divided with $(q \cdot d x) / g$ and a replacement for $S(x, t)$, this is obtained:

$$
\begin{aligned}
\frac{\partial^{2} u(x, t)}{\partial t^{2}} & =\frac{g \cdot E \cdot A}{q} \cdot \frac{\partial^{2}}{\partial x^{2}}\left(u(x, t)+b_{\mathrm{f}} \cdot \frac{\partial u(x, t)}{\partial t}\right) \\
& +g \pm a .
\end{aligned}
$$

In Eqs. (2) and (3), (E) is the rope elasticity modulus whose magnitude depends on the elasticity modulus of wires $\left(E_{\mathrm{r}}=2.1 \cdot 10^{5} \mathrm{MPa}\right)$ and the construction of the rope [17] and [18], whose value can be twice smaller (stranded wire ropes).

By using the differential equation, (Eq. (4)) and the equilibrium condition of moments on the driving pulley, it is possible to form a system of equations that describes a dynamic equilibrium on the driving pulley in the case of a model shown in Fig. $4 \mathrm{~b}$ in this form [12] and [19]:

$$
\begin{aligned}
\frac{q}{g} \cdot \frac{\partial^{2} u_{1}(x, t)}{\partial t^{2}} & =E \cdot A \cdot \frac{\partial^{2}}{\partial x^{2}} \cdot\left[u_{1}(x, t)+b_{\mathrm{f}} \cdot \frac{\partial u_{1}(x, t)}{\partial t}\right] \\
& +q \cdot\left(1 \pm \frac{a}{g}\right)
\end{aligned}
$$

$$
\begin{aligned}
\frac{q}{g} \cdot \frac{\partial^{2} u_{2}(x, t)}{\partial t^{2}} & =E \cdot A \cdot \frac{\partial^{2}}{\partial x^{2}} \cdot\left[u_{2}(x, t)+b_{\mathrm{f}} \cdot \frac{\partial u_{2}(x, t)}{\partial t}\right] \\
& +q \cdot\left(1 \pm \frac{a}{g}\right),
\end{aligned}
$$

$$
\begin{aligned}
M_{\mathrm{m}}= & \frac{R}{i \cdot \eta} \cdot E \cdot A \cdot \frac{\partial}{\partial x} \\
& \cdot\left\{u_{1}\left(l_{1}, t\right)-u_{2}\left(l_{2}, t\right)+b_{\mathrm{f}} \frac{\partial}{\partial t}\left[u_{1}\left(l_{1}, t\right)-u_{2}\left(l_{2}, t\right)\right]\right\} \\
& -J_{\mathrm{r}} \cdot \frac{a \cdot i}{R} .
\end{aligned}
$$

\subsection{Boundary Conditions}

In order to solve a partial differential equation, (Eq. (7)), i.e., an equation system (Eqs. (5) to (7)), it is necessary to define the boundary conditions in the incoming point of the rope to the pulley in the meeting point of hoist ropes and the elevator cabin.

Boundary conditions at point $\mathrm{C}$, where the rope makes the first contact with the pulley, are dependent on whether the winding is with or without rope slipping. Fig. 6a shows the distribution of the forces on the wrap angle of the pulley $(\alpha)$ for a quasistatic case of elevator operation (without the influence of dynamic forces). The regular elevator operations must not allow for the rope to slip in the whole wrap angle $(\alpha)$, which is regulated with a safety degree against slipping, i.e., with the existence of a suitable angle $\left(\alpha_{\mathrm{M}}\right)$ with the so-called relative abeyance of the rope on a driving pulley. It should be noted that, in quasistatic conditions, the zone with the elastic slipping of the rope on a driving pulley $\left(\alpha_{\mathrm{K}}\right)$, Fig. 6a, always occurs on the descending side. However, due to the oscillation, the force in the incoming end changes, so slipping is probable in the pulley's incoming zone. The change of force in the wound rope part can only be maintained if this change is smaller than the adhesive force making it possible. Fig. 6d shows different cases of force distribution over the wound rope length as a function of elevator velocity. With high-speed elevators, it should be expected that the force change in the wound part of the rope is smaller than the friction force change in the incoming zone (curve $v_{3}$, Fig. 6d). Basically, in this case, it can be accepted that there is no slipping in the rope and rope pulley meeting point. The problem is analysed in great detail in [12] and briefly summarized in [20].

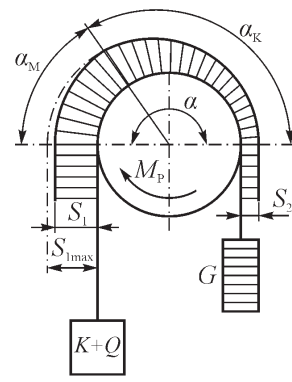

a)

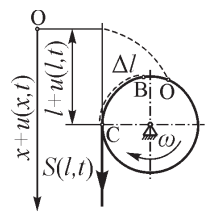

b)

d)

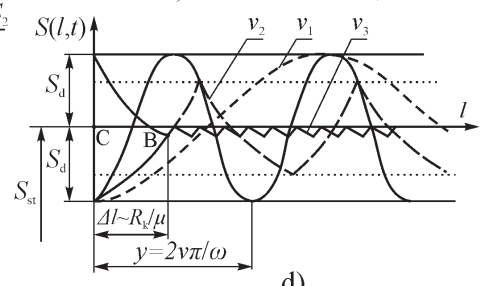

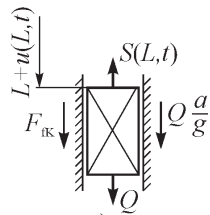

c)
Fig. 6. Boundary conditions; a) force distribution on the wrap angle of the pulley, b) driving pulley without slipping, c) cage (cabin), d) different cases of the force distribution 
The boundary condition at the meeting place of the rope and the pulley without slipping, Fig. $6 \mathrm{~b}$ (point C), is presented in this form:

$$
u(l, t)=\int_{0}^{t} \frac{\partial u(l, t)}{\partial x}\left(\frac{\mathrm{d} l}{\mathrm{~d} t}\right) \mathrm{d} t .
$$

The boundary condition in the meeting point of the rope and elevator cabin (mine elevator cage) or counterweight is given in this form:

$$
\begin{aligned}
Q= & E \cdot A \cdot \frac{\partial}{\partial x}\left(u(L, t)+b_{\mathrm{f}} \cdot \frac{\partial u(L, t)}{\partial t}\right) \\
& +\left(\frac{Q}{g} \cdot \frac{\partial^{2} u(L, t)}{\partial t^{2}}-a\right)-F_{\mathrm{f}},
\end{aligned}
$$

where is $F_{\mathrm{f}}=-\mu \cdot F_{\mathrm{N}} \cdot \operatorname{sign}(v)$ friction force between sliding guide shoes and guide rails.

\subsubsection{Estimation of Critical Velocity}

The non-integrated boundary condition (Eq. (8)) prevents the solution of the partial differential equation (Eq. (5)) so that the solution can be sought through the formation of integral equations, which contain both the differential equations and the corresponding boundary conditions. Simplifying the mathematical model, friction within the boundary condition is omitted in Eq. (9).

In Fig. 7, a weightless fibre is shown, loaded at point $(S)$ by the force $S_{i}$, where the displacement of the rope point (without sliding over the drive pulley) in the region $s<x$, shows a linear increase from zero to the boundary value $u(s)$, while the displacement below point $S$ is stable and equal to the boundary value $u(s)$. Therefore, for the elemental force $\left(S_{i}=1\right)$, there is a deformation:

$$
K(x, s)=\left\{\begin{array}{ll}
\frac{x-l}{E \cdot A} & \text { for } s>x \\
\frac{s-l}{E \cdot A} & \text { for } s<x
\end{array},\right.
$$

and displacement $u(x)=K(x, s) \cdot S_{i}$.

For the case with several acting forces with acting points at $x=s_{i}$ there is a displacement:

$$
u(x)=\sum_{i=1}^{n} K\left(x, s_{i}\right) \cdot S_{i} .
$$

For the load case with evenly distributed rope load (rope's weight), there is the expression:

$$
u(x)=\int_{l}^{L} K(x, s) \cdot q \cdot \mathrm{d} s .
$$

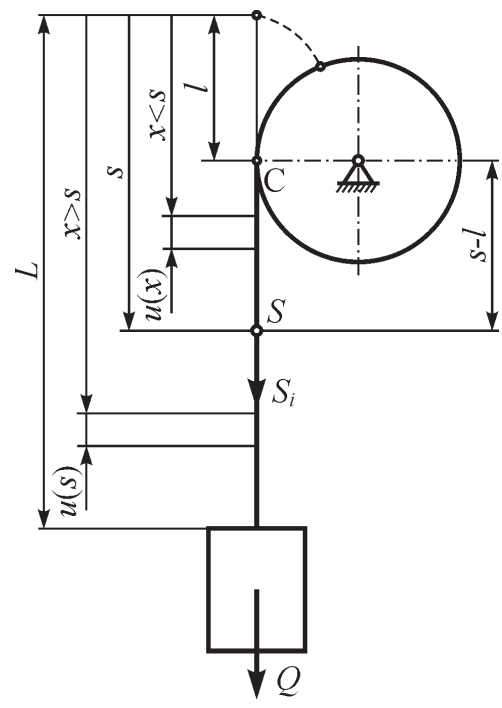

Fig. 7. Deformation of a rope

By applying this procedure to the differential equation (Eq. (5)), replacing the floating argument with $(s)$, multiplying by the function $K(x, s, l)$ and performing the necessary mathematical transformations, the rope deformation in the form is obtained [20]:

$$
\begin{aligned}
u(x, t) & =-\int_{l}^{L} K(x, s, l) \cdot q(s) \cdot\left(\frac{\partial^{2} u}{\partial t^{2}}-g-a\right) \mathrm{d} s \\
& +\int_{0}^{t} \frac{\partial u(l, t)}{\partial x} v(t) \mathrm{d} t+E \cdot A \int_{l}^{L} K(x, s, l) \frac{\partial^{3} u}{\partial s^{2} \partial t} \mathrm{~d} s \\
& -b_{\mathrm{f}} \cdot E \cdot A \cdot \frac{\partial^{2} u(L, t)}{\partial x \partial t} \cdot K(x, L, l) .
\end{aligned}
$$

Using the method of particular integrals, taking into account only the first form of oscillations of the rope and that the length of the free rope $(L-l)$ changes "slowly" with time, and if a new variable $v(x, t)$ is introduced, so that:

$$
u(x, t)=v(x, t)+u(l, t),
$$

the deformation of rope free side in the phase of loadlifting will be:

$$
\begin{aligned}
v(x, t) & =(x-l) \cdot h_{0} \cdot\left(\frac{L-l_{0}}{L-l}\right)^{1 / 4} \cdot e^{m} \cdot \cos \left(\int_{0}^{t} \omega(l) \mathrm{d} t\right) \\
& +\frac{x-l}{E \cdot A} \cdot\left(Q+\frac{q \cdot(2 \cdot L+x+l)}{2}\right) \cdot\left(1+\frac{a}{g}\right),
\end{aligned}
$$

where:

$$
h_{0} \cong-\frac{Q}{E \cdot A} \cdot \frac{a}{g},
$$




$$
\begin{aligned}
\omega^{2}(l) & =\frac{g \cdot E \cdot A}{\left[Q+\frac{q \cdot(L-l)}{3}\right] \cdot(L-l)}, \\
m & =-\frac{b_{\mathrm{f}}}{2} \cdot \int_{0}^{t} \omega^{2}(l) \cdot \mathrm{d} t .
\end{aligned}
$$

Analysing Eq. (7), it can be concluded that during the reduction of the free length of the rope (loadlifting), its deformation can increase under certain conditions, which causes a permanent increase in the dynamic load of the hoist rope. Such a phenomenon, which is usually described as unstable lifting, will not occur if the lifting velocity is less than the critical velocity, which is defined by the expression:

$$
v_{\mathrm{kr}}=2 \cdot b_{\mathrm{f}} \cdot \frac{g \cdot E \cdot A}{Q+\frac{q \cdot(L-l)}{3}}=2 \cdot b_{\mathrm{f}} \cdot \frac{E \cdot A}{M_{\mathrm{e}}},
$$

where $M_{\mathrm{e}}=\left(Q+\frac{q \cdot(L-l)}{3}\right) / g$ is the reduced mass of the cabin and the rope part as a "heavy spring".

The level of critical velocity depends on the damping characteristic of the wire rope and the elevator-s basic characteristics. When it comes to elevators with high load capacity, high velocity and lifting height (high-speed elevators and mine elevators), the lifting velocity can exceed the critical velocity, which is why it is necessary to check the stability of the lifting process already in the design phase. It should be taken into account that Eq. (15) does not contain the friction in guide rails, which adds to the oscillation reduction, and simultaneously increases the critical velocity value.

\section{EXPERIMENTAL DETERMINATION OF DYNAMIC PARAMETERS}

Experimental studies shown in this paper represent the sequel to the research in [13]. The measuring was done on a mine elevator in RTB Bor, Serbia; the maximum projected cage lifting velocity was $16 \mathrm{~m} / \mathrm{s}$, and the projected lifting height was $523 \mathrm{~m}$ in the first phase and $763 \mathrm{~m}$ in the second phase of mining. The driving mechanism is shown in Fig. 8. The other significant characteristics of this exploitation machine can be seen in Tab. 1.

A mine shaft is like a round cross-section with a $10 \mathrm{~m}$ diameter. The transfer of the driving moment to the hoist ropes is done through friction (Köepe system) from the grooved drum with a $2.5 \mathrm{~m}$ diameter.
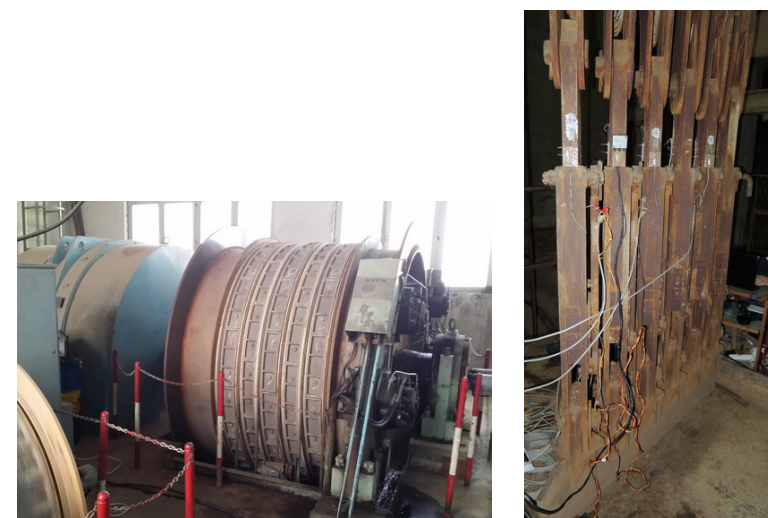

Fig. 8. Driving machine of a mine elevator and the connecting

\begin{tabular}{|c|c|}
\hline $\begin{array}{l}\text { Driving electric } \\
\text { motor }\end{array}$ & $\begin{array}{l}\text { Power: } 1500 / 2860 \mathrm{~kW} \text {, } \\
\text { number of revolutions: } 122.2 \mathrm{rpm} \text {, } \\
\text { torque: } 117.2 / 233.4 \mathrm{kNm}\end{array}$ \\
\hline Cage (cabin) & $\begin{array}{l}\text { Mass: } 13 \mathrm{t} \text { (it includes the cage and the connecting } \\
\text { tools for connecting the hoist ropes), Fig. } 8\end{array}$ \\
\hline Counterweight & Mass: $21 \mathrm{t}$ \\
\hline Hoist ropes & $\begin{array}{l}z=6 \text { pieces, } \\
d=27 \mathrm{~mm} \text { ( } 150 \text { wires per cross-section). } \\
\text { Lang's lay ropes, three right-hand Lang's lay ropes, } \\
\text { and three left-hand Lang's lay ropes. } \\
\text { Breaking force: } 561 \mathrm{kN} \text {, tensile strength of the } \\
\text { wires: } 1700 \mathrm{MPa} \text {. } \\
\text { Unit mass: } 3.02 \mathrm{~kg} / \mathrm{m} \text {. }\end{array}$ \\
\hline $\begin{array}{l}\text { Compensation } \\
\text { ropes }\end{array}$ & $\begin{array}{l}z=2 \text { pieces, } \\
d=50 \mathrm{~mm} \text { ( } 222 \text { wires per cross-section). } \\
\text { Connected with the cage via rotating hooks to } \\
\text { prevent unwinding. Unit mass: } 9.64 \mathrm{~kg} / \mathrm{m} \text {. }\end{array}$ \\
\hline
\end{tabular}
tools for connecting the hoist ropes and the cage

Table 1. Mine elevator technical characteristics

\subsection{Equipment Used and the Method for Measuring Data} Acquisition

The following measuring equipment was used for the mine elevator experiment:

- Universal 8-channel measuring amplifier (2 pieces), QUANTUM X MX480B, pos. 10a and 10b (Fig. 9),

- A computer for storing the measuring signals, pos. 13 (Fig. 9),

- Antennas for the wireless transfer of the measuring signal (2 pieces) NanoStation loco NS2L, made by IBIQUITI NETWORKS; $5 \mathrm{~km}$ range with the antennas optical visibility, pos. 12a and $12 b$ (Fig. 9),

- Incremental encoder - the number of revolutions sensor AINS 41, made by Meyer IndustrieElectronic $\mathrm{GmbH}$ - MEYLE; measuring range up 
to $6000 \mathrm{rpm}$ and with an allowed axial/radial load at the output shaft of $30 / 20 \mathrm{~N}$, pos. 9 (Fig. 9),

- Optical measuring device for the number of revolutions ROS type, made by Monarch Instrument; measuring range varies from 1 to 250 000 rpm, pos. 1 (Fig. 9),

- Accelerometer HBM B12, pos. 2 (Fig. 9),

- Strain gauges HBM LY41-6/120, pos. 3 to 8 (Fig. 9),

- Software for acquisition and processing of measuring signals, HBM catmanEasy-AP.

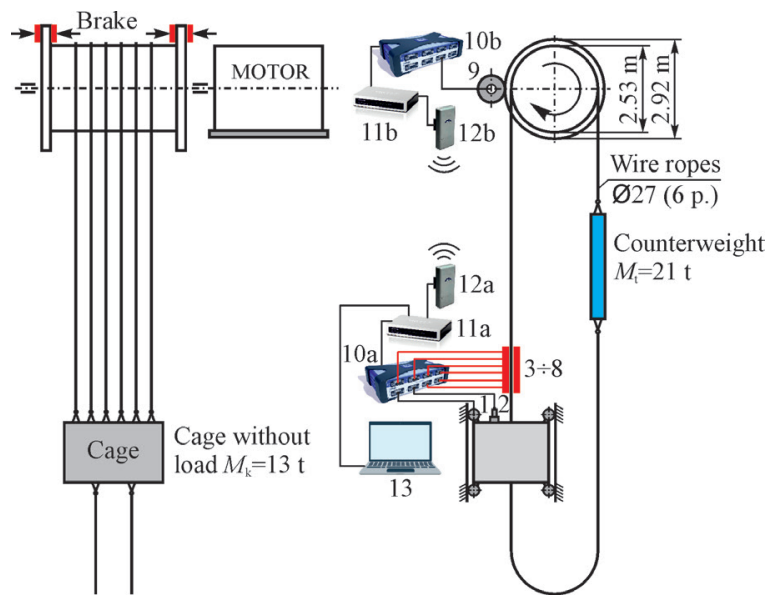

Fig. 9. Schematic layout of the measuring places

The experiment was done according to the principle of summary data acquisition via a wireless data transfer by using the NanoStation loco NS2L antennas (pos. 12a and 12b, Fig. 9). In this way, a complete synchronization of the collected data on the cage roof and machine room was achieved. The drum number of revolutions was measured with an AINS 41 incremental encoder (pos. 9, Fig. 9). It was set on the adaptive carrier with a $127 \mathrm{~mm}$ diameter measuring wheel, which was directly leaned onto the rim of the brake disc, Fig. 10a. The encoder measuring signal was led to the amplifier (pos. 10b, Fig. 9), and then via a LAN switch (pos. 11b, Fig. 9) and the antenna (pos. 12b, Fig. 9) wirelessly connected to the other radio antenna positioned on the cage (pos. 12a, Fig. 9). The measuring signal was stored in a common computer file (pos. 13, Fig. 9) placed on the cage. It was done via another LAN switch (pos. 11a, Fig. 9).

The lifting and lowering of the velocity of the cage was measured via a roller guide, whose change in the number of revolutions was registered with an optical sensor (pos. 1, Fig. 9), positioned on a small magnet table, Fig. 10b. The change in the cage's acceleration during the measuring process was registered by an HBM B12 accelerometer (pos. 2, Fig.
9), set on the connecting tools of the cage through a magnetic holder, Fig. 11a. The force changes in the hoist ropes were monitored by measuring the deformation of the connecting tools (pos. 3 to 8, Fig. 9). The deformations were measured on each connecting tool (out of 6 in total) by using the HBM LY41-6/120 strain gauges, Fig. 11b.

a)
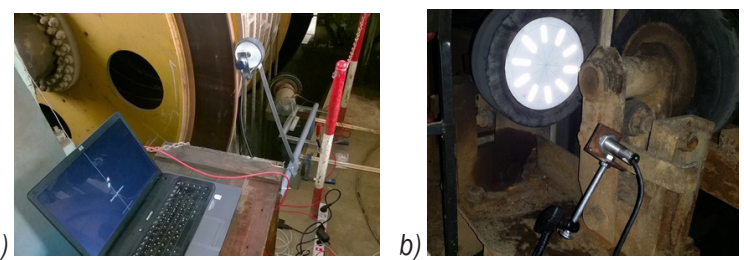

Fig. 10. Measuring places; a) the incremental encoder connected with the measuring wheel positioned on the rim of the brake disc, and b) the optical sensor (number of revolutions sensor) positioned on the cage
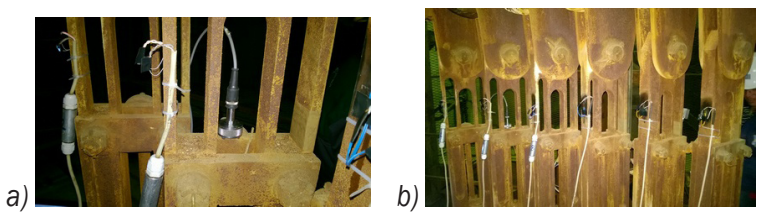

Fig. 11. Measurements on the cage connecting tools; a) cage acceleration, and b) deformations

All measuring signals were led to the other eightchannel measuring amplifier (pos. 10a, Fig. 9), and they were recorded on the computer (pos. 13, Fig. 9) via a LAN switch (pos. 11a, Fig. 9).

\subsection{Protocols and Results of the Experiment}

In Fig. 12, a schematic layout of a mine shaft elevator is shown with labelled levels, whose positions were set with altitude, using plus and minus. The ground level was at an altitude of $+436 \mathrm{~m}$, while the machine room was placed at $+465 \mathrm{~m}$.

Experiment results and determination of the dynamic model parameters in this paper are shown in four characteristic motion cases (lifting and lowering) of the cage, with and without load. A significantly higher number of measurements was completed for different cases (different positions for starting and stopping the cage motion etc.), and the results are presented in [11]. Here, the results of the lowering and lifting of an empty cage and a loaded cage (traction machine) are presented. According to those, the system oscillation parameters are defined. The characteristics of experimental cases are as follows:

I. Lowering an empty cage from position $+104 \mathrm{~m}$ to position $+56 \mathrm{~m}(48 \mathrm{~m})$. The action of 


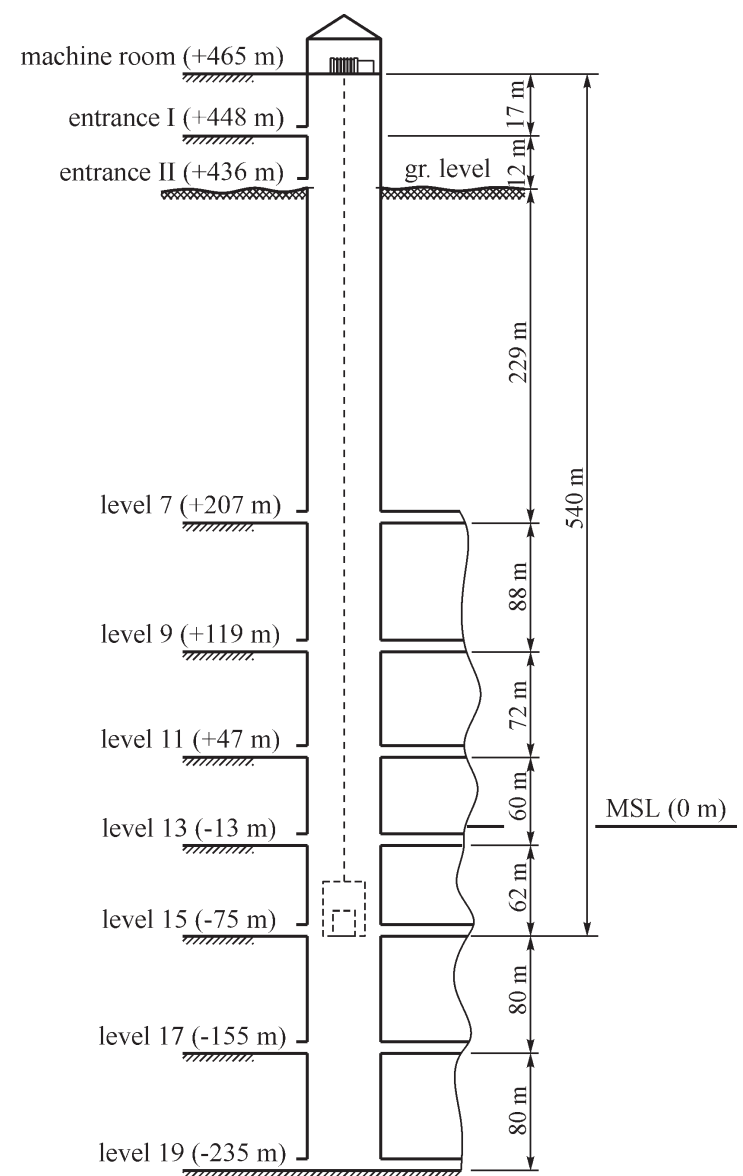

Fig. 12. Schematic layout of a vertical mine shaft in "Jama" mine of RTB Bor

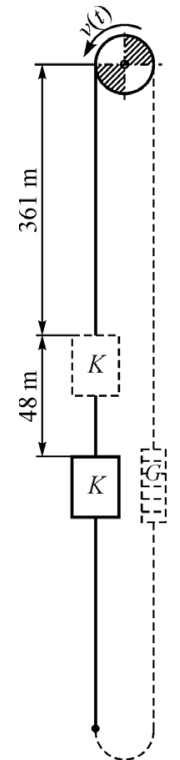

a)

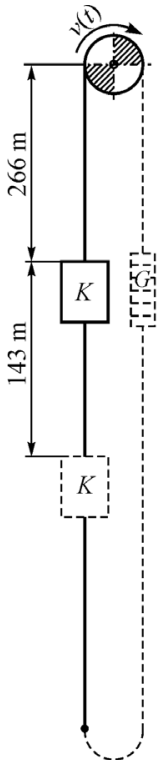

b)

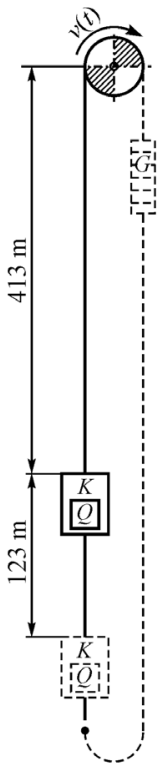

c)

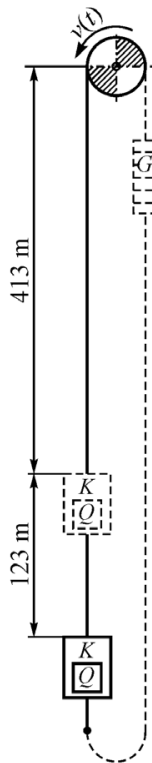

d)
Fig. 13. Mine elevator parameters that are relevant for the analysis; a) lowering an empty cage, b) lifting of an empty cage, c), lifting a loaded cage, d) lowering the loaded cage stopping the cage was performed by suddenly switching off the driving electromotor (at a high velocity, Fig. 13a).

II. Lifting of an empty cage from position $+56 \mathrm{~m}$ to a position $+199 \mathrm{~m}(143 \mathrm{~m})$. Stopping the cage was done just like in the case above, with the sudden switching off the power to the driving electromotor, at a high velocity, Fig. 13b.

III. Lifting a loaded cage (the traction machine for wagons, mass $\sim 9.35 \mathrm{t}$ ) from position a $-71 \mathrm{~m}$, to position $+52 \mathrm{~m}(123 \mathrm{~m})$. Stopping the cage was done at a low speed, Fig. 13c.

IV. Lowering the loaded cage (the traction machine for wagons, mass $\sim 9.35 \mathrm{t}$ ) from position $+52 \mathrm{~m}$ to $-71 \mathrm{~m}(123 \mathrm{~m})$. Stopping the cage was done at a low speed, Fig. $13 \mathrm{~d}$.

The results of the conducted experimental research can be seen in the following figures, which are showing the changes in the winding velocities of hoist ropes that were wound onto the drum; cage acceleration and changes in the forces in the hoist ropes, i.e., on the elements for connecting the ropes to the cage. The results are valid for all four chosen examples of motion. The diagram shows the character of the changes of the said parameters. It shows the cage oscillation amplitudes that occur after stopping the driving machine. This part of the diagram (after stopping the driving machine) is used to set the mechanical characteristics of steel ropes (harmonic oscillations).

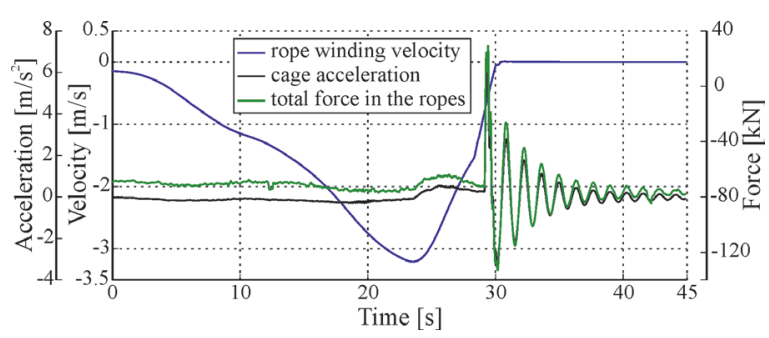

Fig. 14. Diagram with the results obtained during lowering an empty cage and sudden stopping, at a "high" velocity (I motion case)

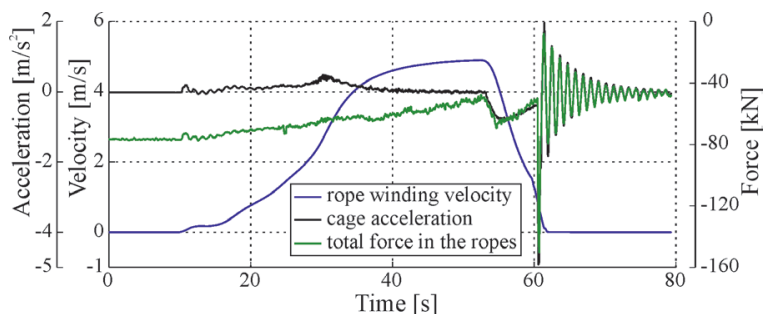

Fig. 15. Diagram with the results obtained during lifting the empty cage and sudden stopping at a "high" velocity (II motion case) 


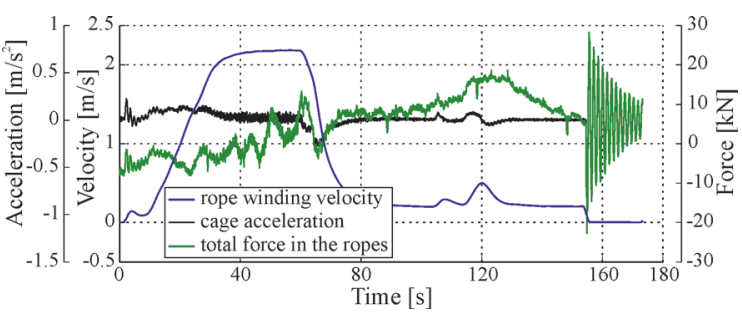

Fig. 16. Diagram with the results obtained during the loaded cage lifting process (III motion case)

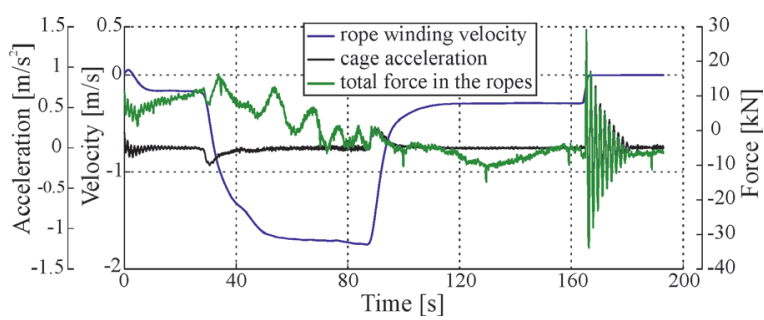

Fig. 17. Diagram with the results obtained during loaded cage lowering process (IV motion case)

\subsection{Determination of Dynamic Parameters Based on Measurement Results}

The stiffness and damping parameters can be determined, and the elasticity modulus as mechanical characteristics of a steel rope can be indirectly determined too, by using the above diagrams and determining the oscillation period, i.e., the frequency and logarithm decrement of the damping. In [13], and especially in [17], the said characteristics are described in detail, so this study only mentions the important parts for explaining the results obtained with new measurements.

Stiffness and elasticity modulus. Rope stiffness is defined with an expression [13]:

$$
c=\frac{E \cdot A}{L-l(t)} .
$$

The stiffness depends on the change in the rope's free length, but it also depends on the elasticity modulus, usually taken as a constant parameter in dynamic behaviour analyses. However, due to the complex construction of a steel rope (consisting of wires, strands, and a core), its change depending on the strain magnitude and loading character (loadingunloading) cannot be neglected. According to [18], a distinction can be made between the so-called tangent elasticity modulus $\left(E_{\mathrm{t}}\right)$ and an average (medium) elasticity modulus between two stresses $\left(E_{\mathrm{S}}\right)$, Fig. 18. The tangent elasticity modulus represents a theoretical angle of the inclination of the tangent to the $\sigma-\varepsilon$ curve for the current stress value $\left(\sigma_{\mathrm{Z}}\right)$. The constant variability in the elasticity modulus magnitude can be observed, and significant differences occur in loading and unloading the rope. The average (median) value of elasticity modulus can be set for boundary working stresses $-E_{\mathrm{S}}\left(\sigma_{\text {lower }}, \sigma_{\text {upper }}\right)$.

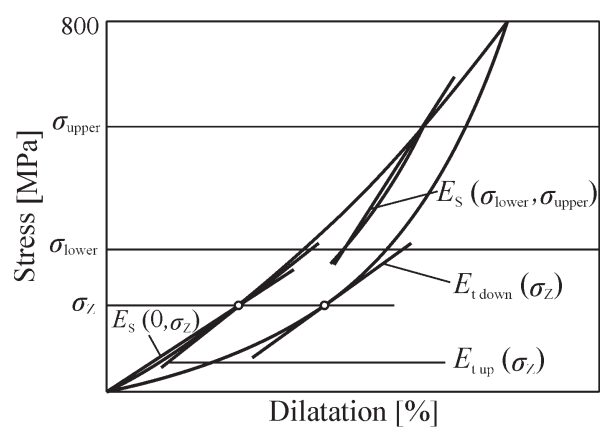

Fig. 18. Tangent and average rope elasticity modulus

Damping. In many practical systems, oscillation energy is gradually transformed into heat or sound, the effect mostly known as damping. Although the quantity of such energy is relatively small, it is important to dedicate some attention to damping to predict the oscillatory system's response, such as the elevator systems considered in this paper.

Damping at the elevator is complex, and it happens because of the rope's inner friction (viscous and hysteretic damping), Coulomb's friction on guide rails and damping due to the airflow around the cabin (cage) in the elevator shaft [13] and [15].

Since the presented experiment results (Tab. $2)$ refer to the moment of stopping the cage $(v=0)$, damping as a consequence of airflow around the cage can be neglected.

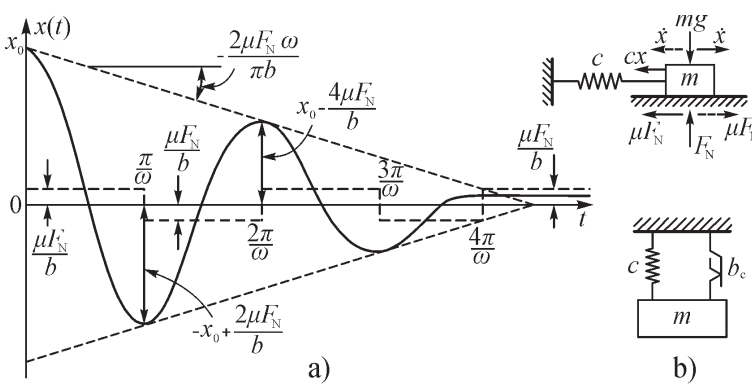

Fig. 19. An oscillating system with Coulomb's friction;

a) motion with the load, b) a model with Coulomb's damping

The friction on the elevator guide rails creates the damping force (Coulomb's friction), which is constant in its magnitude, but it is of the opposite direction compared to the motion of the oscillating load. Since this type of elevator requires special attention to be paid to the guiding accuracy and reducing the guide 
rails friction, in the example with centrical cabin load, the friction forces can be neglected in relation to the total load. Nevertheless, the influence can be of importance for cabin oscillation analyses [21]. A typical diagram of an oscillator with Coulomb's friction is presented in Fig. 19a. The declining of amplitudes, as opposed to inner friction oscillation, is linear in its nature [15] and [17].

As it was explained in [13], the total force of Coulomb's friction on guide rails is:

$$
F_{\mathrm{c}}=n_{\mathrm{v}} \cdot n_{\mathrm{t}} \cdot \mu \cdot F_{\mathrm{N}} \cdot
$$

For the most part, the literature presents the inner friction in the rope as viscous friction, like in homogenous bodies, Figs. 2a and b. Nevertheless, while the rope is being deformed, the energy dissipation also appears due to the friction between wires and strands, which slide against one another during the deformation process. This creates the hysteresis loop (Fig. 20a). The effect causes the damping known as hysteretic or structural damping. The loss of energy per unit of material volume in one loading and unloading cycle is equal to the area closed by the hysteresis loop. Experiments have confirmed that the energy loss per cycle is approximately proportional to the square of the oscillating amplitude. A model with hysteretic damping is presented in Fig. 20b. Similarly to the above, the rope's inner friction $\left(b_{\mathrm{r}}\right)$ is a combination of viscous and hysteretic damping, Fig. 20c.

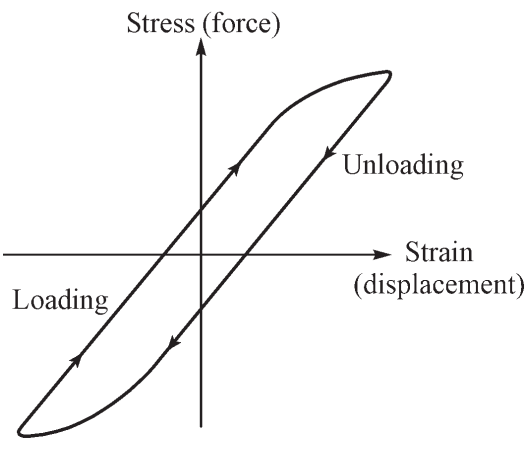

a)

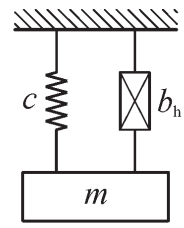

b)

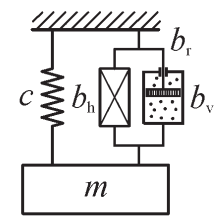

c)
Fig. 20. Hysteretic damping; a) hysteresis loop, b) a model with hysteretic damping, and c) an equivalent model with internal rope damping

The total damping of the considered system is an overall influence of the damping due to the rope's internal friction and the damping caused by the friction in guide rails, so it can be represented by the parallel connections in the oscillator model, Fig. 21b. This is seen in the diagrams shown in Figs. 14 to 17, which show the cumulative influence of rope's internal friction and the guide rails' friction is generally of a viscous damping character.

The size of the impact caused by rope damping and damping due to guide rails friction can be defined via the "overlapping" of the diagram measurement results and simulation results, as presented in Fig. 22.

Based on the theory about free harmonic damping oscillations (Fig. 21a), it is concluded that for determining the dynamic parameters, one should take the part of the cage oscillation diagram after the driving machine is stopped.
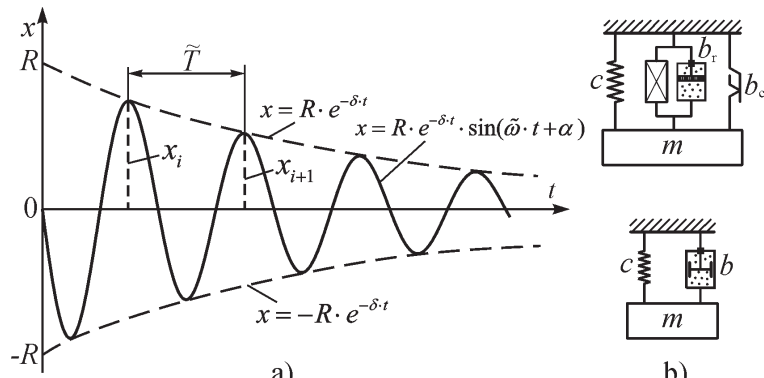

b)

Fig. 21. Oscillating system with viscous integral damping; a) damped oscillations b) a lifting system model

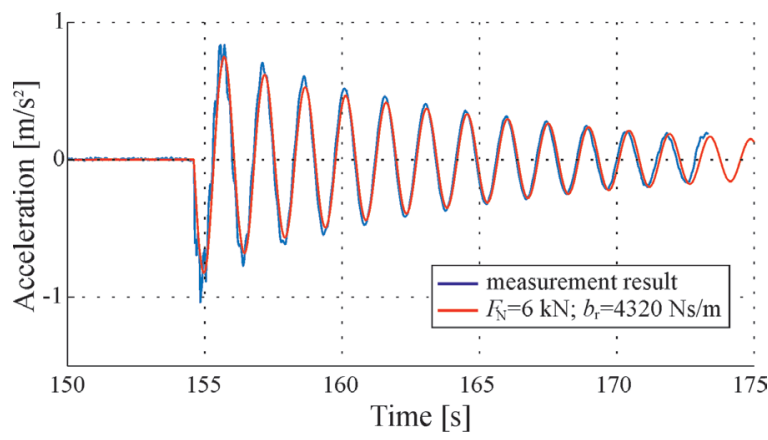

Fig. 22. The impact of inner and Coulomb's friction on oscillating systems when $b=5161 \mathrm{Ns} / \mathrm{m}$ (Table 2)

By measuring the amplitudes and oscillating periods of free damping oscillations (changes in cage acceleration), the damping coefficient $(\delta)$ can be determined via a logarithmic decrement, and based on this, a resistance force coefficient $(b)$ :

$$
\begin{gathered}
D=\ln \frac{x_{i}}{x_{i+1}}=\frac{1}{n} \ln \frac{x_{i}}{x_{i+n}}=\delta \cdot \tilde{T} \rightarrow \delta=\frac{D}{\tilde{T}}, \\
b=2 \cdot \delta \cdot M_{\mathrm{e}} .
\end{gathered}
$$

Determining the stiffness coefficient (c) and elasticity modulus $(E)$ of hoist ropes can be performed 
Table 2. Values obtained by measuring and parameters of hoist ropes

\begin{tabular}{lcccccccc}
\hline & $L[\mathrm{~m}]$ & $M_{\mathrm{e}}[\mathrm{kg}]$ & $\delta\left[\mathrm{s}^{-1}\right]$ & $\omega[\mathrm{rad} / \mathrm{s}]$ & $c[\mathrm{~N} / \mathrm{m}]$ & $b[\mathrm{Ns} / \mathrm{m}]$ & $E[\mathrm{MPa}]$ & $\delta / \omega$ \\
\hline I (Fig. 13a) $\downarrow$ & 409 & 18797 & 0.33 & 4.67 & 409163 & 12222 & 98440 & 0.070 \\
\hline II (Fig. 13b) $\uparrow$ & 266 & 20525 & 0.21 & 5.69 & 663329 & 8718 & 103792 & 0.037 \\
\hline III (Fig. 13c) $\uparrow$ & 413 & 28099 & 0.09 & 4.26 & 510803 & 5161 & 124095 & 0.022 \\
\hline IV (Fig. 13d) $\downarrow$ & 536 & 26613 & 0.18 & 3.88 & 401206 & 9639 & 126498 & 0.047 \\
\hline
\end{tabular}

with the measured oscillation parameters (oscillating period, oscillating amplitudes, etc.):

$$
\begin{gathered}
c=M_{\mathrm{e}} \cdot \omega^{2}, \\
E=\frac{c \cdot L}{A} .
\end{gathered}
$$

Fig. 23 is an illustration of determining the said mechanical characteristics of hoist ropes based on the cage acceleration changes diagram (after the driving machine was stopped) in the III motion case.

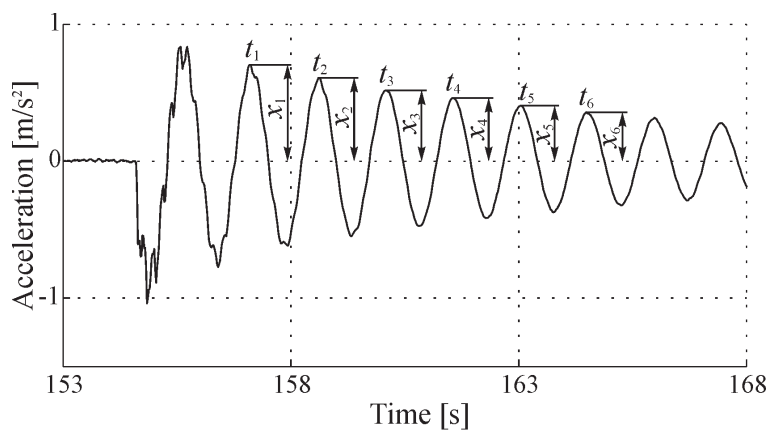

Fig. 23. The measured values of cage acceleration for III motion case

Based on the diagram in Figs. 14 to 17 and the expressions (Eq. (18) to (21)), mechanical characteristics of steel ropes are defined, as shown in Table 2. Upon analysing the measured results, it can be concluded that the data for elasticity modulus are in agreement with the data from the literature [18]. The higher values of elasticity modulus for loaded cabins are seen as a consequence of the rope constructed by putting the lays of wires in strands and strands into a rope. This confirms the validity of the applied procedure, enabling us to define the real (exploitation) values in mine elevators. The damping coefficient values, for which there is no significant comparative data, are not constant in size but appear to be different in the analysed experiments. Regarding the limitations in conducting the experiments in working conditions, it was concluded that the experiment should be prepared in a laboratory setting in the future.

\subsection{Computer Simulations of Mine Elevator Dynamic Behaviour and Result Correlation}

In order to simulate the mine elevator operation process, the study has set the change in hoisting rope velocity at the point of winding onto the driving drum as the change (diagram), obtained by direct measuring on the driving machine via an incremental encoder (pos. 9, Fig. 9).

An oscillation diagram was separated with the purpose of verifying the dynamic model during the whole period while the cage was moving, as well as after the complete stop in the driving machine moving. The acceleration diagram in the III motion case is shown, "overlapping" the diagram with the measured results, Fig. 24.

Judging by the diagram in Fig. 24, it can be concluded that the dynamic model with dynamic parameters, determined by the measuring with satisfactory accuracy, shows the real behaviour of a mine elevator. As a result, this makes computer simulations possible, which will analyse the real loads of the exploitation facility [11] and [22]. The described method is a new approach that will ensure the analysis of dynamic behaviour in systems for vertical hoisting, which can be found in exploitation.

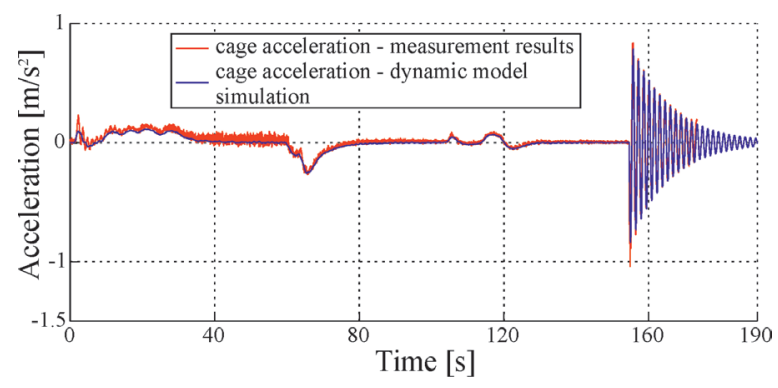

Fig. 24. Cage acceleration diagrams in the motion case III (Fig. 13c)

After comparing the results of numerical analysis with measurement results, a conclusion arises that it would be useful to have some form of numerical value for result correlation. In the literature, this value is known as Pearson's correlation coefficient. This 
study did not determine the correlation coefficient for individual motions, so that it could be taken as one of the ideas for future research.

As an illustration of the possibility of dynamic analysis, the following section shows diagrams that represent changes in individual values. They were created in specialized software for dynamic analysis using the experimental data shown in Table 2.

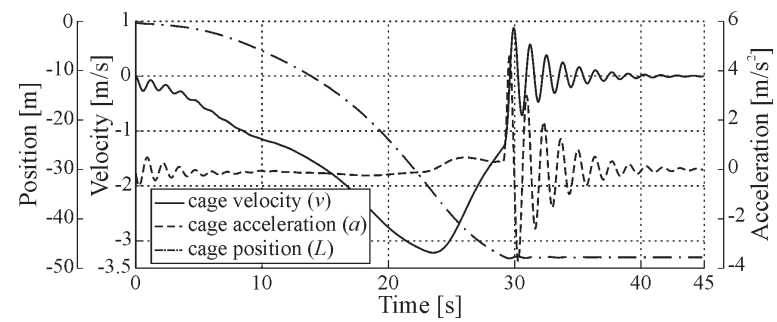

Fig. 25. Diagram showing the changes in the cage position, velocity, and acceleration, for I motion case

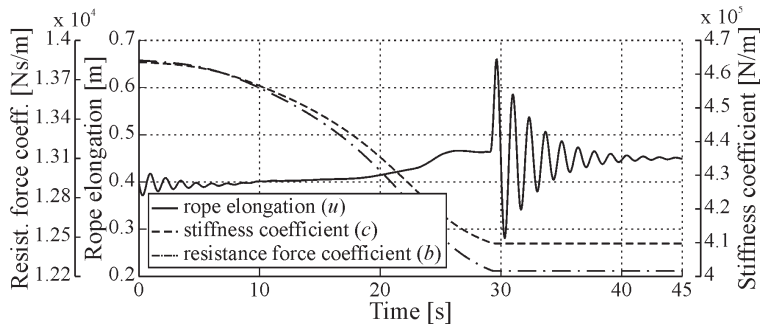

Fig. 26. Comparative diagrams showing the changes in the elongation, stiffness coefficient, and resistance force coefficient of hoist ropes, for I motion case

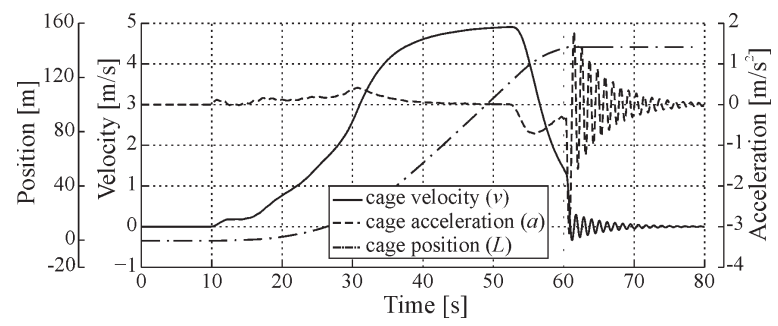

Fig. 27. Diagram showing the changes in cage position, velocity, and acceleration, for II motion case

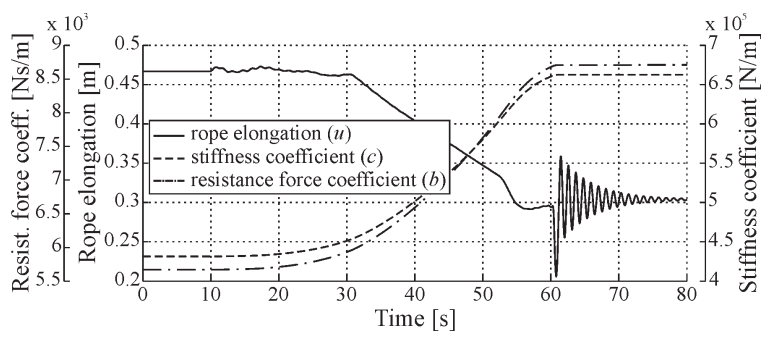

Fig. 28. Comparative diagrams showing the changes in the elongation, stiffness coefficient, and resistance force coefficient of hoist ropes, for II motion case

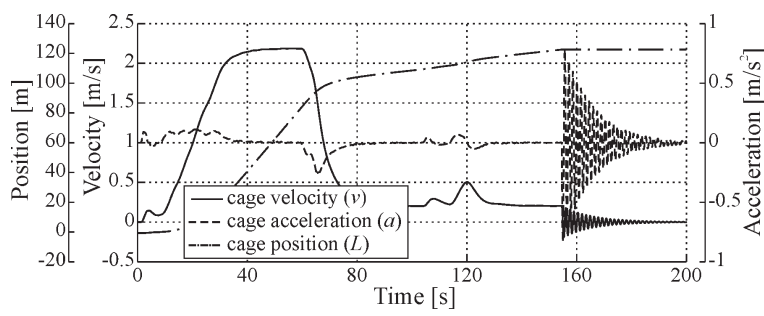

Fig. 29. Diagram showing the changes in cage position, velocity, and acceleration, for III motion case

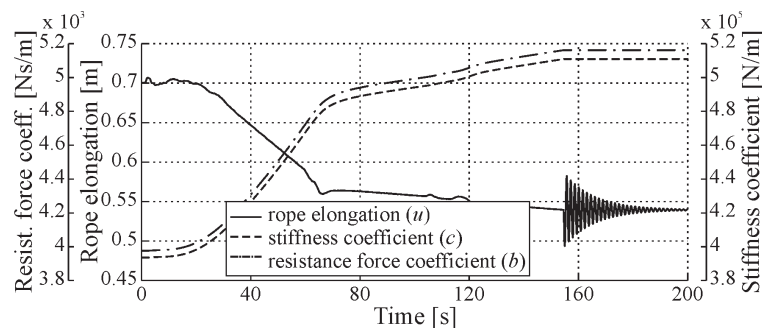

Fig. 30. Comparative diagrams showing the changes in the elongation, stiffness coefficient, and resistance force coefficient of hoist ropes for III motion case

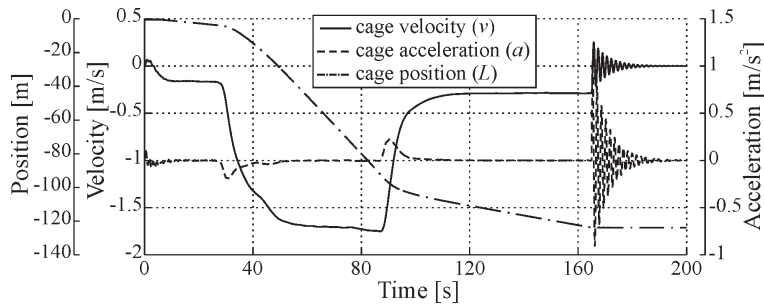

Fig. 31. Diagram showing the changes in cage position, velocity, and acceleration for IV motion case

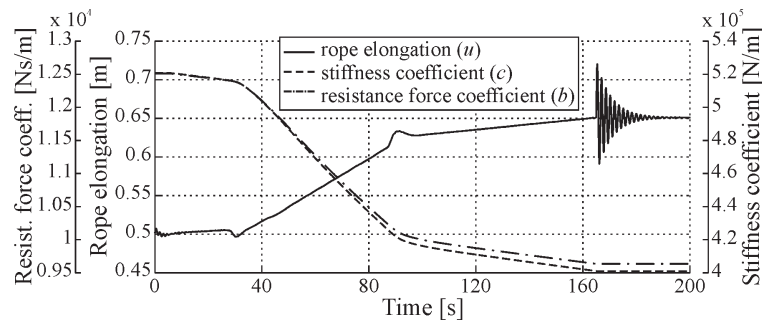

Fig. 32. Comparative diagrams showing the changes in the elongation, stiffness coefficient, and resistance force coefficient of hoist ropes for IV motion case

\section{AN ANALYSIS OF THE HOISTING VELOCITY IMPACT AS THE BASIS FOR CONTROL SYSTEM}

The material of this paper confirms that there are different analyses of individual parameters for vertical hoist systems. One part is of special interest, and that is the research on the changes in hoist velocities, i.e., defining the control system [23]. The above method can be used for determining an optimal form 
for changing the hoist velocity, to reach maximum capacity, i.e., the shortest time for the motion, along with securing a high level of motion, especially in modern passenger elevators, whose velocities reach up to $20 \mathrm{~m} / \mathrm{s}$. As stated above, the dynamic parameters during the elevator or exploitation facility design process can only be determined with limited accuracy, so the exploitation deviation can be significant. The method shown in this paper can be used as a basis, which shows that it is possible to apply straightforward methods and form an optimal elevator facility. The application of the illustrated method makes it possible to determine real parameters and perform dynamic analysis even after the installation process. Therefore, the method makes it possible to adjust and correct the exploitation facility and improve the previously defined optimal operating conditions. This particularly concerns defining the appropriate control program, which ensures the shortest motion time with the maximum level of comfort, i.e., with the control of the dynamic loads.
The following figures present some of the possible ways of impacting driving kinematic characteristics through a control program. Fig. 33 shows how the changes in velocity form characteristics can impact the cabin (cage) oscillating amplitudes, as well as the motion comfort. As it appears, it is important to note that by controlling the drive in the acceleration period, and especially by choosing the right moment to switch from acceleration to stationary velocity, the system can be significantly "relieved", i.e., the motion comfort can be bettered (the amplitudes can be quite decreased), pos. 4 in Fig. 33.

Installing an acceleration transducer (accelerometer) on the points where ropes connect with the cabin (cage) has acceleration change as a response at any moment. This is vital with high-speed elevators, in cases in which nominal velocity is not reached between two neighbouring floors, but the acceleration is followed by braking, Fig. 34 .

The right control is key for braking at the most convenient moment, as shown by line (2) in the

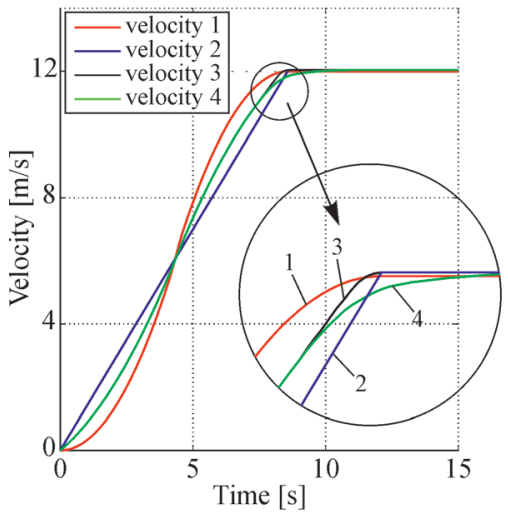

a)

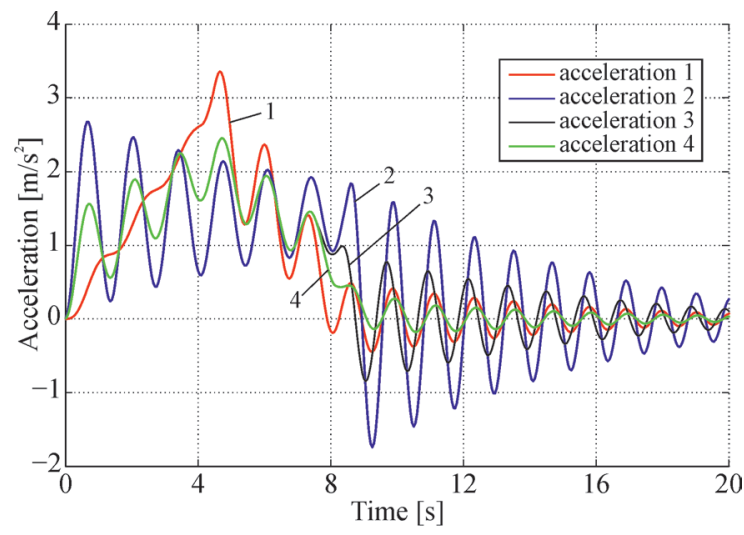

b)

Fig. 33. The influence of driving system kinematic characteristics on the motion comfort; a) change of velocity, b) change of acceleration

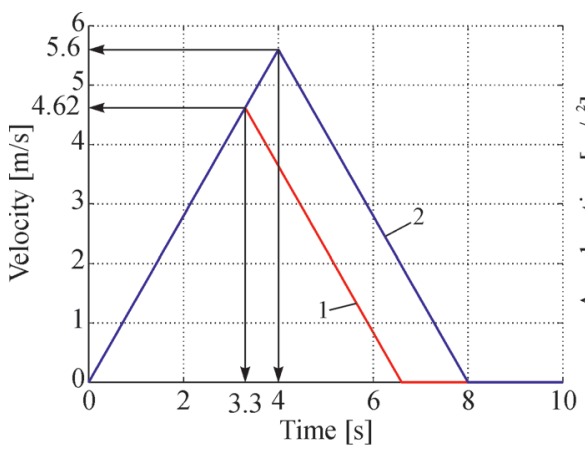

a)

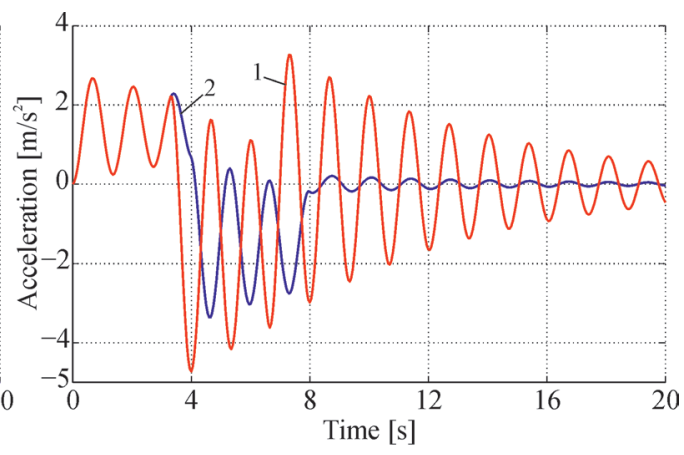

b)

Fig. 34. The layout of the influence of controlling the magnitude of oscillating system amplitudes; a) change of velocity, b) change of acceleration 
velocity change diagram, Fig. 34a, which causes much smaller oscillating amplitudes, Fig. 34b. The distance the cabin (cage) has passed and the accuracy of station landing must be taken into account when creating a control system.

\section{CONCLUSION}

The dynamic analysis and scientific approach shown in this paper are of special importance taking into account the nature of the systems; they are meant for lifting (lowering) people and load to great heights (depths) at velocities up to $20 \mathrm{~m} / \mathrm{s}$. The complexity of the dynamic analysis can also be seen because these are oscillating processes with variable parameters and boundary conditions at the incoming/outgoing points of the steel rope and the driving pulley. Furthermore, the stiffness and elasticity modulus of steel ropes are not constant in magnitude but rather change depending on the changes in cage position, as well as construction, stress, and rope exploitation time.

The dynamic model that is suitable for the analysis can be formed by observing a particular system and by simplifying (i.e., omitting) the small values of higher order.

The presented approach on forming the differential motion equation for the incoming end of the rope onto the driving pulley helps determine the critical hoisting velocity in the function with mechanical characteristics (elasticity modulus and damping) and stress (load) in steel ropes. Moreover, this method also makes it possible to execute computer simulations and dynamic behaviour analysis during the motion by using the appropriate specialized software for the dynamic analysis of mechanical systems.

The paper presents an experimental method that can be used to determine dynamic parameters such as stiffness, elasticity modulus, and damping in exploited elevator steel ropes. Specific elasticity modulus values presented in Table 2 reveal the noticeable dependence on the load, i.e., rope stress. In addition, the damping coefficient in ropes is not a constant size, but it depends on the position of a cage. It can be deduced that ropes experience a combination of viscous damping and hysteretic damping, which should be further investigated in these systems.

By forming adequate dynamic models, determining real values for dynamic parameters, and simulations of dynamic behaviour for real facilities, it is possible to define the basis for a program that would control the driving mechanism. That would ensure minimal dynamic loads, which is especially relevant for comfort during the motion, while simultaneously securing the optimal motion time, i.e., the efficiency of high-speed passenger elevators, especially in transient operation regimes.

As for mine elevators, strict safety conditions are required in order for the facility to operate, especially regarding elevators for the transport of people. It is necessary to secure special conditions at the moment of power transfers and friction motion to avoid the slipping of the rope as a whole along the driving pulley. Finally, this is vital from the point of view of defining suitable boundary conditions for a dynamic model at the points where the ropes get on or off the driving pulley.

\section{NOMENCLATURES}

$u_{1}, u_{2} \quad$ elastic deformation of the rope on the incoming and outgoing rope end, [mm]

$E$ rope elasticity modulus, [MPa]

$A$ rope's cross-section area, $\left[\mathrm{mm}^{2}\right]$

$a$ acceleration of the driving mechanism, $\left[\mathrm{m} / \mathrm{s}^{2}\right]$

$M_{\mathrm{m}}$ driving motor torque, $[\mathrm{Nm}]$

$i$ gear ratio, [-]

$\eta \quad$ driving mechanism efficiency, [-]

$J_{\mathrm{r}} \quad$ moment of inertia of rotational masses, reduced to the shaft of a driving pulley, $\left[\mathrm{kgm}^{2}\right]$

$R \quad$ driving pulley radius, [m]

$q$ rope weight per meter, $[\mathrm{kg} / \mathrm{m}]$

$l \quad$ wound rope length, [m]

$v \quad(v=\mathrm{d} l / \mathrm{d} t)$ circumferential velocity, $[\mathrm{m} / \mathrm{s}]$

$F_{\mathrm{f}}$ friction force between sliding guide shoes and guide rails, $[\mathrm{N}]$

$l_{0} \quad$ length of winded rope at time $t=0,[\mathrm{~m}]$

$n_{\mathrm{v}} \quad\left(n_{\mathrm{v}}=4\right)$ number of the roller guide groups, [-]

$n_{\mathrm{t}} \quad\left(n_{\mathrm{t}}=3\right)$ number of rollers in the guide group, [-]

$\mu$ rolling resistance of the roller guide on the guide rail, [-]

$F_{\mathrm{N}}$ force of the roller guide pressure on the guide rail for centric load, which depends on the spring tightening during installation, [N]

$x_{i} \quad\left(\right.$ also, $x_{i+1}$ and $\left.x_{i+n}\right)$ measured oscillating amplitudes, [mm]

$\tilde{T} \quad$ measured oscillating period of free damping oscillations, [s]

$M_{\mathrm{e}}$ reduced oscillating mass $\left(M_{\mathrm{e}}=M+(q \cdot L(\mathrm{t})) / 3\right)$, $[\mathrm{kg}]$

$M$ total mass hanging on hoist ropes (loaded cage and compensation ropes), $[\mathrm{kg}]$

$L(t)$ hoist ropes' free length $\left(L(t)=L-\int v(t) \mathrm{d} t\right),[\mathrm{m}]$

$v(t)$ circumferential velocity of the pulley (drum), $[\mathrm{m} / \mathrm{s}]$ 
$\omega$ circular frequency of free oscillations $\left(\omega=\sqrt{\tilde{\omega}^{2}+\delta^{2}}\right),[\mathrm{rad} / \mathrm{s}]$

$\tilde{\omega}$ damping oscillation frequency $(\tilde{\omega}=2 \pi / \tilde{T})$, $[\mathrm{rad} / \mathrm{s}]$

$L \quad$ hoist ropes length, [m]

$\delta \quad$ damping coefficient, $\left[\mathrm{s}^{-1}\right]$

$c$ ropes stiffness coefficient, $[\mathrm{N} / \mathrm{m}]$

$b$ resistance force coefficient, $[\mathrm{Ns} / \mathrm{m}]$

\section{REFERENCES}

[1] Peng, Q., Xu, P., Yuan, H., Ma, H., Xue, J., He, Z., Li, S. (2020). Analysis of Vibration Monitoring Data of Flexible Suspension Lifting Structure Based on Time-Varying Theory. Sensors, vol. 20, no. 22, 6586, Dol:10.3390/s20226586.

[2] Zhang, Q., Yang, Y., Hou, T., Zhang, R. (2019). Dynamic analysis of high-speed traction elevator and traction car-rope time-varying system. Noise \& Vibration Worldwide, vol. 50, no. 2, p. 37-45, DOI:10.1177/0957456519827929.

[3] Bao, J., Zhang, P., Zhu, C. (2011). Modeling of Rope Longitudinal Vibration on Flexible Hoisting System with Time-Varying Length. Applied Mechanics and Materials, vol. 130-134, p. 2783-2788, DOl:10.4028/www.scientific.net/ AMM.130-134.2783.

[4] Zhang, Y., Pota, H.R., Agrawal, S.K. (2002). Modification of residual vibrations in elevators with time-varying cable lengths. Proceedings of the American Control Conference Anchorage, vol. 6, p. 4962-4966, Dol:10.1109/ACC.2002.1025450.

[5] Arrasate, X., Kaczmarczyk, S., Almandoz, G., Abete, J.M., Isasa, I. (2014). The modelling, simulation and experimental testing of the dynamic responses of an elevator system. Mechanical Systems and Signal Processing, vol. 42, no. 1-2, p. 258-282, DOl:10.1016/j.ymssp.2013.05.021.

[6] Herrera, I., Su, H., Kaczmarczyk, S. (2010). Investigation into the damping and stiffness characteristics of an elevator car system. Applied Mechanics and Materials, vol. 24-25, p. 7782, D0l:10.4028/www.scientific.net/AMM.24-25.77.

[7] Kimura, H., Ito, H., Nakagawa, T. (2007). Vibration analysis of elevator rope (Forced vibration of rope with time-varying length). Journal of Environment and Engineering, vol. 2, no. 1, p. 87-96, DOI:10.1299/jee.2.87.

[8] Guo, Y., Zhang, D., Chen, K., Feng, C., Ge, S. (2018). Longitudinal dynamic characteristics of steel wire rope in a friction hoisting system and its coupling effect with friction transmission. Tribology International, vol. 119, p. 731-743, DOl:10.1016/j.triboint.2017.12.014.

[9] Watanabe, S., Okawa, T. (2018). Vertical vibration of elevator compensating sheave due to brake activation of traction machine. Journal of Physics: Conference Series, vol. 1048, no. 012012, DOI:10.1088/1742-6596/1048/1/012012.
[10] Li, C., Hua, C., Qin, J., Zhu, Z. (2019). Research on the Dynamic Characteristics of High-Speed Elevator System. Advances in Engineering Research, vol. 181, p. 105-109, D0l:10.2991/ ice2me-19.2019.23.

[11] Đokić, R. (2016). Dynamics researching and development of vertical transport machines using numerical-experimental procedures. PhD thesis, University of Novi Sad, Faculty of Technical Sciences, Novi Sad.

[12] Vladić, J. (1982). Contribution to the determination of the safety degree against slipping of a dynamically loaded rope in the power transmission system by a driving pulley. MSc thesis, University of Novi Sad, Faculty of Technical Sciences, Novi Sad.

[13] Vladić, J., Jovanović, M., Đokić, R., Kljajin, M., Karakašić, M. (2015). Theoretical and experimental analysis of elevator dynamic characteristics. Tehnički vjesnik / Technical Gazette, vol. 22, no. 4, p. 1011-1020, D0I:10.17559/TV20150107175453.

[14] Vladić, J., Đokić, R., Kljajin, M., Karakašić, M. (2011). Modelling and simulations of elevator dynamic behaviour. Tehnički vjesnik / Technical Gazette, vol. 18, no. 3, p. 423434.

[15] Rao, S. S. (2011). Mechanical vibrations. Prentice Hall, Upper Saddle River.

[16] Sinha, A. (2010). Vibration of Mechanical Systems. Cambridge University Press, Cambridge.

[17] Vladić, J., Đokić, R., Jovanović, M. (2019). Steel wire rope and computational-experimental procedures for the analysis of specific transport machines. University of Novi Sad, Faculty of Technical Sciences, Novi Sad.

[18] Feyrer, K. (2007). Wire Ropes. University of Stuttgart, Stuttgart.

[19] Goroshko, O.A. (2007). Evolution of the dynamic theory of hoist ropes. International Applied Mechanics, vol. 43, no. 1, p. 64-67, DOI:10.1007/s10778-007-0007-9.

[20] Vladić, J., Malešev, P., Šostakov, R., Brkljač, N. (2008). Dynamic analysis of the load lifting mechanisms. Strojniški Vestnik - Journal of Mechanical Engineering, vol. 54, no. 10, p. 655-661.

[21] Zhang, X., Li, H., Meng, G. (2008). Effect of Friction on the Slide Guide in an Elevator System. Journal of Physics: Conference Series, vol. 96, no. 012074, D0l:10.1088/17426596/96/1/012074.

[22] Vladić, J., Đokić, R. (2017). Characteristics of mathematical methods and specialized software systems for dynamic analysis of elevators and mining elevators. IMK-14 - Research and development in Heavy Machinery, vol. 23, no. 2, p. 31-38, DOl:10.5937/imk1702031v.

[23] Knezevic, B.Z., Blanusa, B., Marcetic, D.P. (2017). A synergistic method for vibration suppression of an elevator mechatronic system. Journal of Sound and Vibration, vol. 406, p. 29-50, D0I:10.1016/.j.jsv.2017.06.006. 